\title{
Aspectos fisiopatológicos da febre nas doenças infecto-parasitárias
}

\author{
Marco Tulio Antônio García-Zapata* \\ Edson Sidião de Souza Júnior ${ }^{* *}$
}

RESUMO - A febre constitui uma resposta defensiva do organismo a agressões e é um dos achados mais freqüentes na clínica médica. Possui diversas etiologias, e, por isso, pode estar presente em patologias de diversas origens. Entre estas, destacamos as doenças infecto-parasitárias, nas quais a febre geralmente é o primeiro sintoma. É uma resposta integrada de fatores endócrinos e autônomos, coordenada pelo centro regulador da temperatura: o hipotálamo. Para conhecer esse complexo mecanismo fisiopatológico da febre é necessário conhecer os mecanismos fisiológicos básicos que regulam a temperatura corporal, bem como os recursos físicos disponíveis para sua mensuração. Os fatores intrínsecos da geração da febre, assim como seus mecanismos fisiopatológicos, serão analisados e descritos nessa revisão, com ênfase à febre nas doenças infecto-parasitárias.

Palavras-chave: Febre. Fisiopatologia. Doenças infecto-parasitárias.

\section{Physiopathological aspects of the fever in infectious parasitics diseases}

\begin{abstract}
The fever constitutes a defensive mechanism of the organism to aggressions. It is one of the most frequent findings in the medical clinic. It is associated with several etiologies, can be present in several pathologies. Among these, we detach the infectious and parasitic diseases, where the fever is usually the first symptom to appear. It is an integrated mechanism of endocrine and autonomous factors, coordinated by the temperature regulator center: the hypothalamus. To know this complex physiopathological mechanism of the fever it is needed before to know the basic physiological mechanisms that regulate the corporal temperature, as the available physical resources for the temperature measurements. The intrinsic factors of the fever generation and their physiopathological mechanisms will be analyzed and described with emphasis to the fever in the infectious parasitic diseases.
\end{abstract}

Keywords: Fever. Physiopathology. Infectious diseases. Parasitic diseases.

\footnotetext{
Professor Titular e Pesquisador do Instituto de Patologia Tropical e Saúde Pública da Universidade Federal de Goiás, Goiânia - GO. Caixa Postal 12911 - Setor leste Vila Nova. CEP 74643-970 GoiâniaGO, BRASIL. Fones: (62) 209-6120; (62) 241-3961; (62) 9971-9452 Fax: (62) 521-1839 E-mail: zapata@iptsp.ufg.br; mctulian1@ hotmail.com

** Doutorando, Instituto de Patologia Tropical e Saúde Pública da Universidade Federal de Goiás, Goiânia - GO. E-mail: sidiao@iptsp.ufg.br
} 


\section{Introdução}

A febre é uma síndrome na qual o sintoma predominante é a hipertermia, estando freqüentemente associada à astenia, à taquicardia e à oligúria. Durante a história, os homens consideravam a febre como sinal benéfico na ocorrência de uma infecção. Hipócrates, que considerava o homem era formado por quatro humores: sangue, muco, bílis amarela e bílis negra, afirmava que a febre era resposta a um desequilíbrio destes humores quando produzidos em excesso, constituindo-se no elemento responsável pela eliminação desse excesso (CABALLERO; HERRERA, 1999). A febre, dois mil anos depois, já não era considerada um sinal tão benéfico, graças aos trabalhos do fisiologista francês, Claude Bernard, demonstrando que os animais morriam quando a temperatura corporal excedia de 5 a $6^{\circ} \mathrm{C}$. No entanto, trabalhos in vitro sugerem que algumas defesas imunológicas funcionam mais eficientemente a temperaturas febris que normais. Para os médicos galênicos, a febre é considerada por si só como uma doença, e, portanto o principal fator a ser tratado. Para a medicina moderna, a febre indica a presença de doença subjacente com diferentes origens entre as quais infecciosa, neoplásica, auto-imune ou induzida por drogas, sendo, portanto, estas, o principal alvo do tratamento. Pelas diversas etiologias, a febre é um dos achados mais freqüentes na prática clínica.

Os fatores intrínsecos da geração da febre, assim como seus mecanismos fisiopatológicos, serão analisados e descritos nessa revisão, com ênfase à febre nas doenças infecto-parasitárias.

\section{Desenvolvimento}

O principal meio de mensuração da temperatura corpórea, o termômetro, foi introduzido na medicina há, aproximadamente, 130 anos, mas o estudo das diversas curvas térmicas iniciou-se no final do século XVIII. Apesar dos grandes avanços tecnológicos a mensuração da temperatura corpórea ainda traz grandes subsídios no diagnóstico clínico. 
Para conhecer os mecanismos geradores da febre, são necessários conhecimentos sobre a fisiologia humana no controle da temperatura corporal. O ser humano tende a manter a temperatura corporal constante, de 36,6 a $37,2^{\circ} \mathrm{C}$, mesmo com as variações da temperatura ambiental. A temperatura corporal varia conforme o local e o período da mensuração. Quando a mensuração é realizada na boca, a temperatura normal está entre $36^{\circ}$ e $37,8^{\circ} \mathrm{C}$, enquanto a mensuração no reto é, em média $0,6^{\circ} \mathrm{C}$ maior. A temperatura axilar varia entre $36^{\circ}$ e $37,8^{\circ} \mathrm{C}$. Existem variações de temperatura corpórea no homem de acordo com a periodicidade, sendo observados níveis mais baixos pela manhã e mais elevados no final da tarde. Vários processos fisiológicos podem influenciar a temperatura corpórea, destacando-se o envelhecimento, o ciclo menstrual, a gravidez e a atividade física.

A manutenção da temperatura corpórea dá-se por mecanismos que equilibram a perda e a produção de calor. O hipotálamo se constitui na principal estrutura anátomofuncional na cascata dos complexos mecanismos implicados no controle da temperatura corporal e na febre. A atividade metabólica é a maior fonte de calor do organismo. Entre os fatores que intensificam o metabolismo, está a febre, já que o aumento de $1^{\circ} \mathrm{C}$ na temperatura corporal produz elevação de $10 \%$ do metabolismo basal. A dissipação do calor ocorre pela evaporação d' água (respiração e sudorese), condução, convecção e radiação pelo corpo.

O hipotálamo é formado por uma porção anterior da área pré-óptica, constituída por células nervosas sensíveis à temperatura do sangue arterial. Duas áreas destacam-se nesta porção: uma anterior ( o centro dissipador de calor), que provoca maior dissipação de calor e outra posterior (centro promotor de calor), que gera e conserva calor. As vias eferentes do centro dissipador atuam na vasodilatação periférica e no aumento da sudorese, enquanto as vias do centro promotor realizam a vasoconstrição periférica, aumentam a atividade metabólica corporal (via supra-renal e atividade simpática), além do aumento do tônus muscular (calafrios).

É necessário fazer um diagnóstico diferencial da febre com a hipertermia. Este constitui um estado termal que quase nunca se produz como conseqüência de uma infecção, e, portanto não representa um mecanismo de defesa contra agressões. A hipertermia consiste na elevação da temperatura corporal sem aumento da temperatura do termostato hipotalâmico. Ocorre aumento na produção de calor sem correspondente 
aumento da perda. Na febre, a termorregulação continua atuante, mas com o ponto prefixado deslocado para níveis mais elevados, com ativação do centro promotor de calor. Por este motivo, drogas antipiréticas não atuam em estados de hipertermia, já que têm atuação somente no termostato hipotalâmico alterado.

Vários são os fatores determinantes e geradores da febre; o mais comum é a infecção. A febre ocorre com a produção de pirógenos endógenos (ou citocinas), moléculas protéicas de peso molecular aproximado entre 10.000 e 20.000. Já foram caracterizados vários pirógenos endógenos (BEVILACQUA et al., 1998), entre os quais destacamos a interleucina-1 (IL-1), a interleucina-6 (IL-6), o fator de necrose tumoral (caquetina, TNF), interferon alfa e beta (FNT), proteína $\alpha_{1}$ inflamatória do macrófago (PIM), entre outras. Estas substâncias são produzidas por grande variedade de células do organismo, especialmente aquelas capazes de realizar a fagocitose (essencialmente os macrófagos), no entanto acredita-se que outras células sejam capazes de produzi-las, tais como, granulócitos, monócitos, linfócitos, eosinófilos, hepatócitos, etc. Estes pirógenos endógenos não podem ser confundidos com pirógenos bacterianos (exógenos) (BRASILEIRO FILHO, 2000) sendo distinguidos por produzir febre após período de latência, causar leucopenia, e a injeção repetida do mesmo conduzir ao estado de refratariedade. Para que os pirógenos endógenos sejam liberados pelas células responsáveis pela sua produção, ocorre necessidade de indução, e entre os indutores de pirógenos endógenos, destacamos: as endotoxinas de microorganismos, vírus, bactérias, hormônios (esteróides, progesterona, etiocolanolona), pólen, vacinas, proteínas ou produtos de sua desintegração, etc. Estes agentes indutores estimulam a produção de pirógenos endógenos por estas células. É importante salientar que a febre não é produto do efeito farmacológico destes mediadores químicos no organismo. Os pirógenos endógenos, por meio da interação com elementos sensoriais no órgão vascular da lâmina terminal (OVLT) e outras regiões em torno do cérebro, promovem a síntese de prostaglandinas $E_{2}$ pela estimulação da cicloxigenase. As prostaglandinas $E_{2}$ difundemse e atravessam a barreira hemato-encefálica até a área pré-óptica do hipotálamo, gerando a liberação de citocinas nos sítios terminais e distais dos neurônios responsáveis pelos componentes autonômicos, endócrinos e condutores da resposta febril. Existem evidências de que ocorre produção destas citocinas fora do cérebro. A indução da variação do ponto prefixado hipotalâmico da temperatura está mediada pela 
prostaglandina $E_{2}$. Ao gerar ascensão do ponto prefixado hipotalâmico (Figura 1), estimula-se a produção de calor pelo centro promotor de calor, por meio de seus mecanismos (calafrios, aumento do metabolismo celular e vasoconstrição). O aumento no valor prefixado do hipotálamo desenvolverá mecanismos cuja resultante funcional é a perda de calor, principalmente por vasodilatação e sudorese, que tendem a abaixar a temperatura até a faixa considerada normal. A este fenômeno dá-se o nome de crises e ocorre por diferentes razões fisiológicas, tais como, o controle e ou o desaparecimento do agente causador da febre, o uso de antipiréticos, etc.

Figura 1 - Ponto prefixado e temperatura real em um indivíduo normal e com febre (adaptado de CABALLERO; HERRERA, 1999).

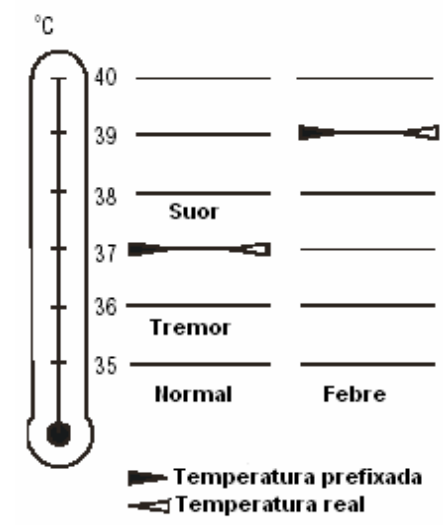

\section{CONSIDERAÇÕES FINAIS}

Várias são as patologias que possuem a febre como importante manifestação clínica (Quadro 1). Independente da etiologia, a febre origina-se pela produção de pirógenos endógenos que ajustam o ponto prefixado do hipotálamo. De origem infectoparasitária, destacamos a málaria (NEVES, 1983), na qual a febre é geralmente contínua ou irregular no início da doença, uma vez que, no indivíduo não-imune, a esquizogonia sanguínea não é sincrônica. Ao final da primeira semana, com o desenvolvimento da resposta imune, a esquizogonia torna-se sincrônica, e a febre tende a ser intermitente, ocorrendo intervalos de apirexia de um dia, nas infecções por Plasmodium vivax, $P$. ovale e $P$. falciparum, e dois dias, nas infecções por $P$. malariae. A febre intermitente é 
de início súbito precedido de calafrios e, em algumas vezes, superior a $40^{\circ} \mathrm{C}$. Ainda que não se conheçam os mecanismos exatos que as geram, as febres são respostas defensivas benéficas ao homem contra diversas agressões, entre elas, as patologias infecto-parasitárias (Figura 2).

Quadro 1 - Principais patologias que apresentam a febre como manifestação clínica e sua etiologia (SCHECHETER; MARANGONI, 1998).

\begin{tabular}{|c|c|}
\hline Patologias com manifestações febris & Etiologia \\
\hline Febres de origem obscura & $\begin{array}{lll}\text { Infecciosas, neoplasias, } & \text { colagenoses, } \\
\text { miscelânea } & & \\
\end{array}$ \\
\hline Sepse & $\begin{array}{llll}\text { Resposta inflamatória à presença } & \text { de } \\
\text { microorganismos }\end{array}$ \\
\hline Leptospirose & Leptospira interrogans \\
\hline Febre amarela & Vírus da febre amarela \\
\hline Dengue & Vírus do dengue \\
\hline Sarampo & Vírus do sarampo \\
\hline Varicela & Vírus Varicella-Zoster \\
\hline Citomegalovirose & Citomegalovírus \\
\hline Coqueluche & Bordetella pertussis e B. parapertussis \\
\hline Rickettsioses & $\begin{array}{ll}\text { Rickéttsias } \quad \text { (bacilos } & \text { Gram-negativos } \\
\text { intracelulares obrigatórios) } & \end{array}$ \\
\hline Malária & $\begin{array}{llll}\begin{array}{l}\text { Plasmodium malariae, } \\
\text { falciparum, } P . \text { ovale }\end{array} & P . & \text { vivax, } & P . \\
\end{array}$ \\
\hline Calazar & Leishmania chagasi, L. amazonensis \\
\hline Estreptococcias & Estreptococos e enterococos \\
\hline Estafilococcias & Estafilococos \\
\hline Febre tifóide & Salmonella sp. \\
\hline
\end{tabular}


Figura 2 - Mecanismo fisiopatológico da febre (adaptado de CABALLERO; HERRERA, 1999).

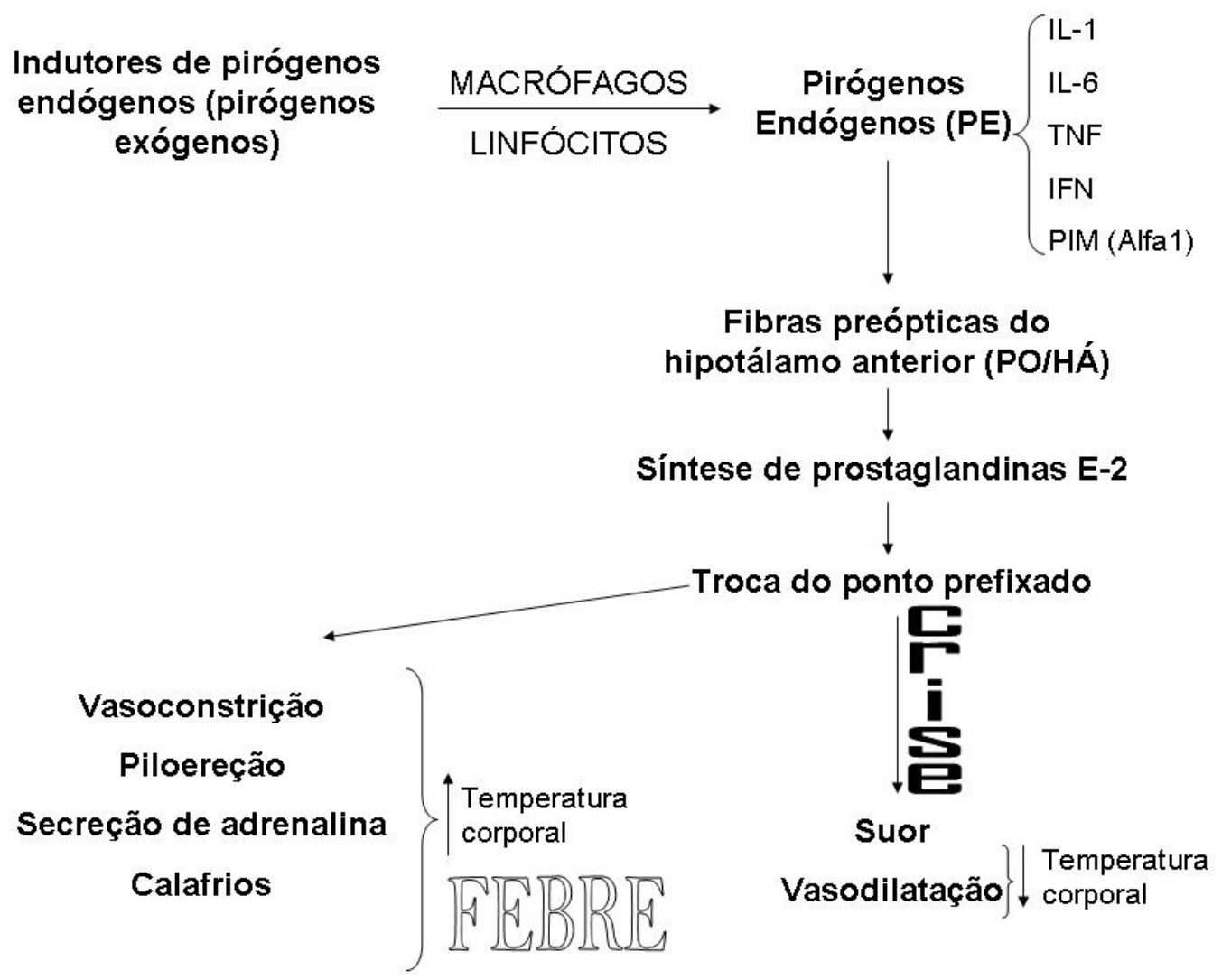

\section{REFERÊNCIAS}

BEVILACQUA, F. et al. Fisiopatologia clínica. 5a . ed. São Paulo: Atheneu, 1998.

BRASILEIRO FILHO, G. Bogliolo Patologia. 6 ${ }^{\text {a }}$ ed., Rio de Janeiro: GuanabaraKoogan, 2000.

CABAllero, L. B. A.; HERRERA, E. E. M. Fisiopatología de la fiebre. Revista Cubana de Medicina Militar, La Habana, v. 28, n.1, p. 49-54, 1999.

NEVES, J. Diagnóstico e tratamento das doenças infectuosas e parasitárias. $2^{\mathrm{a}}$. ed. Rio de Janeiro: Guanabara-Koogan, 1983.

SCHECHETER, M.; MARANGONI, D.V. Doenças infecciosas conduta diagnóstica e terapêutica. Rio de Janeiro: Guanabara-Koogan, 1998. 